\title{
Anthropometry of women of childbearing age in Morocco: body composition and prevalence of overweight and obesity
}

\author{
Rekia Belahsen*, Mohamed Mziwira and Fatima Fertat \\ Laboratory of Physiology Applied to Nutrition and Feeding, Training and Research Unit on Food Sciences, \\ Chouaib Doukkali University, School of Sciences, BP 20, El Jadida 24000, Morocco
}

Submitted 14 May 2003: Accepted 28 October 2003

\begin{abstract}
Objective: To determine the prevalence of obesity and body fat distribution of Moroccan women of childbearing age, using a panel of anthropometric measurements.

Design and setting: A cross-sectional survey conducted in 1995 in an agricultural community, El Jadida province of Morocco. Weight, height, waist and hip circumferences and triceps, biceps, subscapular and supra-iliac skinfold thicknesses were measured. Body mass index (BMI), waist/hip ratio (WHR), sum of all and sum of trunk skinfold thicknesses were determined.

Subjects: In total, 1269 women aged 15-49 years from urban and rural areas were surveyed.

Results: The means of all anthropometric measurements including body fat were higher in urban than in rural women and increased with age. Trunk fat contributed $50 \%$ of total fat. Globally, $4.7 \%$ of women were underweight $\left(\mathrm{BMI}<18.5 \mathrm{~kg} \mathrm{~m}^{-2}\right)$, $35.2 \%$ were overweight or obese (BMI $\geq 25 \mathrm{~kg} \mathrm{~m}^{-2}$ ), $10.1 \%$ were obese (BMI $\geq 30$ $\mathrm{kg} \mathrm{m}^{-2}$ ) and $16.8 \%$ had central obesity (WHR $>0.85$ ). The prevalence of overweight and obesity was higher in the urban than in the rural area. Underweight prevalence decreased with age, whereas that of overweight and obesity increased. All anthropometric parameters adjusted for age increased with the increase of BMI and WHR.

Conclusions: Although undernutrition is still prevalent, there is an alarming prevalence of overweight and obesity in Moroccan women of childbearing age. The results indicate a shift in this country from the problem of dietary deficiency to the problem of dietary excess, and alert one to the necessity of establishing an intervention to prevent obesity-related diseases. It is necessary to address which of the anthropometric variables studied here is the best predictor of obesity-related diseases in this population.
\end{abstract}

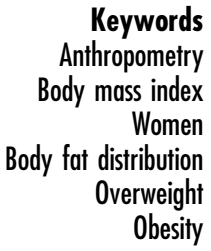

Obesity is a major public health problem in developed countries ${ }^{1}$ and is also becoming increasingly extensive in developing countries undergoing nutrition transition because of changes in diet and lifestyle $\mathrm{e}^{2-5}$. It is a significant cause of morbidity and a factor in mortality owing to its multiple complications that involve hypertension, non-insulin-dependent diabetes mellitus, hypercholesterolaemia and cardiovascular and respiratory diseases ${ }^{1,6,7}$.

To define obesity one should evaluate the fatty mass and locate the level at which excess of this mass increases the risks of mortality and morbidity. The fatty mass can be evaluated by many methods, some of which are expensive, complex and seldom available ${ }^{8}$. The most used and least expensive methods are anthropometric measurements.
Several anthropometric parameters can be used to evaluate body fat and body fat distribution. Body mass index (BMI) is used to determine overall fatness or overall obesity, while waist circumference (WC) and waist/hip ratio (WHR) are used as measures of intra-abdominal fat or central obesity ${ }^{9}$. Nevertheless, WC has been reported to be a better correlate of cardiovascular risk factors than other anthropometric indices ${ }^{7,10,11}$. Indeed, central obesity - especially intra-abdominal fat accumulation is known to be associated with insulin resistance and its related disorders such as diabetes, hypertension and dyslipidaemia $^{12,13}$.

In Morocco, the few epidemiological studies carried out to characterise overweight and obesity have focused mostly on the problem of undernutrition. These studies have reported that the prevalence of overweight and 
obesity has increased in recent years and markedly so in women $^{4,14,15}$. The data available on obesity in the Moroccan population were obtained at the national scale, which does not reflect regional differences in geography, economics, food availability and culture. Moreover, these data used BMI only to estimate overweight and obesity ${ }^{16-18}$; none of the studies conducted anthropometric measurements to determine body fat distribution.

The aims of the present study were to evaluate the prevalence of overweight and obesity in women of childbearing age in an agricultural province of Morocco, using anthropometric measurements, and to assess body fat distribution. These measures are expected to serve as a reference in this country.

\section{Population and methods}

\section{Study population}

A regional cross-sectional survey was conducted in 1995 on an agricultural community of women at reproductive age (15-49 years) in a Moroccan province, El Jadida. The sample was selected randomly from each area of residence (rural or urban). The sample consisted of 1269 nonpregnant women of childbearing age.

\section{Measurements}

The following anthropometric measurements were obtained by trained investigators according to standards recommended by the World Health Organization $(\mathrm{WHO})^{19}$. Weight in light clothes and without shoes was measured to the nearest $0.1 \mathrm{~kg}$ on a mechanical scale. Height to the nearest $0.1 \mathrm{~cm}$ was measured with a stadiometer. WC midway between the lowest rib and the iliac crest and hip circumference at the level of the greater trochanter were measured in duplicate, to the nearest $\mathrm{mm}$, using a flexible tape.

The amount and distribution of body fat were assessed by measuring the thickness of subcutaneous adipose tissue with a Harpenden skinfold calliper. The skinfold thicknesses were measured on the left side of the body at four sites: biceps and triceps (limb), subscapular and supra-iliac (trunk). The sum of the four skinfold thickness measures was considered an indicator of total subcutaneous fat and the sum of trunk skinfold thicknesses as an index of central obesity. BMI was calculated as body weight (in $\mathrm{kg}$ ) divided by the square of height (in $\mathrm{m}$ ). WC and WHR were previously used to assess body fat distribution and specifically as indicators of intraabdominal or visceral fat deposition ${ }^{20-22}$. The WHO cutoff points of $\leq 0.85$ or $>0.85$ for WHR, $80 \mathrm{~cm}$ for WC, and $<18.5 \mathrm{~kg} \mathrm{~m}^{-2}$ (underweight), $18.5-25 \mathrm{~kg} \mathrm{~m}^{-2}$ (normal weight), $>25-30 \mathrm{~kg} \mathrm{~m}^{-2}$ (overweight) and $>30 \mathrm{~kg} \mathrm{~m}^{-2}$ (obese) for BMI were applied. The study protocol was approved by the Moroccan Ministry of Health.

\section{Data analysis}

Summary statistics are used to describe the study population. Mean differences between anthropometric variables according to area of residence and age group were analysed by analysis of variance (Tukey's studentised test). Mean comparisons between anthropometric variables for women according to area of residence, BMI, WHR and WC categories were tested with general linear models adjusted for age. Multiple comparisons were performed with Bonferroni corrections. Associations between different variables were assessed by Pearson's correlation. Statistical significance was set at $P<0.05$. All statistical analyses were performed with the SPSS package (SPSS Inc., Chicago, IL, USA).

\section{Results}

The baseline characteristics of the population sample according to area of residence are presented in Table 1. Mean age was similar in women from both areas of residence; however, all anthropometric measurements including body fat were significantly higher in urban women than in rural women. Trunk fat (sum of trunk skinfold thicknesses) contributed 50\% to total fat (sum of all skinfold thicknesses).

Table 2 presents mean anthropometric measurements of the women according to three age groups: 15-25, 25-35 and $>35$ years. Except for height, all anthropometric measurements increased with age.

Table 3 shows that, overall, $4.7 \%$ of women were underweight, $35 \%$ were overweight or obese (BMI $>25$ $\mathrm{kg} \mathrm{m}^{-2}$ ), 10.1\% were obese and 16.1\% had central obesity (WHR > 0.85). The table shows also that the prevalence of underweight was comparable in childbearing Moroccan women from both areas of residence; however, the prevalence of overweight and obesity was higher in the urban than in the rural area. General obesity (BMI $>30$ $\mathrm{kg} \mathrm{m}^{-2}$ ) and central obesity (WHR $>0.85$ ) were more prevalent in urban $(14.3 \%$ and $19.9 \%)$ than in rural $(6.0 \%$ and $12.4 \%$ ) women.

Table 4 shows that the prevalence of underweight decreased with age whereas that of overweight and general obesity (based on $\mathrm{BMI} \geq 25 \mathrm{~kg} \mathrm{~m}^{-2}$ ) increased, as did the prevalence of intra-abdominal obesity (based on WHR > 0.85). Overweight and obesity (based on BMI) were already prevalent in younger women (15-25 years) (18.1\% and 3.6\%, respectively) and reached higher values after 35 years of age (34.2\% and 19.3\%, respectively). The results also show that, at any age group, underweight and overweight or obesity coexisted.

Mean anthropometric measurements according to BMI and WHR categories are shown in Tables 5 and 6 , respectively. Except for height, the mean values for all anthropometric parameters adjusted for age increased with increasing BMI and WHR. 
Table 1 Anthropometric measurements of Moroccan women of childbearing age, by area of residence

\begin{tabular}{|c|c|c|c|c|c|c|c|}
\hline & \multicolumn{2}{|c|}{$\begin{array}{c}\text { Urban } \\
(n=622)\end{array}$} & \multicolumn{2}{|c|}{$\begin{array}{c}\text { Rural } \\
(n=647)\end{array}$} & \multicolumn{2}{|c|}{$\begin{array}{c}\text { Total } \\
(n=1269)\end{array}$} & \multirow[b]{2}{*}{$P$-value } \\
\hline & Mean & SD & Mean & SD & Mean & SD & \\
\hline Age (years) & 28.9 & 9.7 & 28.3 & 9.9 & 28.6 & 9.8 & 0.223 \\
\hline Height $(\mathrm{cm})$ & 158.8 & 6.0 & 160.5 & 5.9 & 159.7 & 6.0 & \\
\hline Weight (kg) & 62.9 & 13.0 & 60.5 & 10.3 & 61.7 & 11.8 & 0.003 \\
\hline Waist circumference (cm) & 81.5 & 11.1 & 76.6 & 9.1 & 79.1 & 10.4 & 0.000 \\
\hline Hip circumference $(\mathrm{cm})$ & 100.9 & 11.0 & 96.9 & 7.8 & 99.0 & 9.8 & 0.000 \\
\hline \multicolumn{8}{|l|}{ Skinfold thickness (mm) } \\
\hline Triceps & 21.2 & 6.9 & 17.0 & 6.7 & 19.0 & 7.1 & 0.000 \\
\hline Biceps & 15.1 & 6.9 & 8.5 & 4.5 & 11.7 & 6.6 & 0.000 \\
\hline Subscapular & 18.8 & 7.2 & 14.6 & 6.6 & 16.6 & 7.2 & 0.000 \\
\hline Supra-iliac & 16.3 & 6.2 & 13.1 & 7.8 & 14.6 & 7.2 & 0.000 \\
\hline Sum of all skinfold thicknesses (mm) & 71.4 & 23.5 & 53.0 & 21.2 & 62.7 & 24.1 & 0.000 \\
\hline Sum of trunk skinfold thicknesses (mm) & 35.1 & 12.4 & 27.6 & 11.8 & 31.4 & 12.7 & 0.000 \\
\hline BMI $\left(\mathrm{kg} \mathrm{m}^{-2}\right)$ & 24.9 & 5.0 & 23.4 & 3.8 & 24.2 & 4.5 & 0.000 \\
\hline WHR & 0.81 & 0.08 & 0.79 & 0.06 & 0.8 & 0.07 & 0.000 \\
\hline
\end{tabular}

SD - standard deviation; BMI - body mass index; WHR - waist/hip ratio.

Means and SD are unadjusted and were tested for significance with general linear models, controlling for age, with Bonferroni adjustment for multiple comparisons. The mean difference is significant at the 0.05 level.

Using correlation coefficients, BMI, WHR, WC, sum of all skinfold thicknesses and sum of trunk skinfold thicknesses were found to be significantly correlated with all anthropometric measurements (Table 7). The table also shows that central obesity based on WHR and WC was significantly related to parity and education level was negatively correlated to total and trunk fat.

\section{Discussion}

Excess body fat is considered a risk factor for many chronic diseases such as diabetes, hypertension, hyperlipidaemia and cardiovascular diseases ${ }^{23}$. In Morocco, recent statistics have indicated a high prevalence of these diseases (Ministry of Health, Morocco, unpublished) and the prevalence of obesity reached 18\% in 1998/99 according to a national survey in this country ${ }^{16,24}$.

Obesity is characterised by an increased amount of body fat. However, body fat distribution is important given the adverse consequences of obesity on health, especially intra-abdominal fat accumulation, which is found to be an important predictor of cardiovascular risk $6,7,9,10,13,25-28$.

Studies on anthropometry, especially measurements of fatness, among women in North African countries are limited $^{4,14,17}$. Weight, height and BMI are the common indicators used to assess overweight and obesity in this region. However, none of these studies used a wide range of anthropometric measurements to determine body fat distribution in women. Therefore the present study aimed to find the prevalence of overweight and obesity in Moroccan women aged 15-49 years, as well as to assess their body fat distribution using BMI, WHR, WC and skinfold thicknesses as indicators of body composition. As no regional reference data are available for the indicators studied here, $\mathrm{WHO}^{1,29}$ references for BMI and WHR were used to determine body fat distribution and obesity.
The mean values for all data are comparable to those reported in some Arab Gulf populations ${ }^{29,30}$. Our study has revealed that the prevalences of overweight and obesity among childbearing women are about $25 \%$ and $10 \%$, respectively, based on BMI and that except for height, all data are age-dependent. Total body fat as estimated by BMI $\left(\geq 25 \mathrm{~kg} \mathrm{~m}^{-2}\right)$ and visceral fat as estimated by WHR $(>0.85)$ and WC $(\geq 80 \mathrm{~cm})$ begin to accumulate early, in the youngest age group. The same result was suggested for Arab Gulf women ${ }^{29-31}$.

Based on BMI, the prevalence of overweight in the age group $>35$ years was almost double that of the younger age group (15-25 years), whereas obesity prevalence was more than five times higher. Similar trends were found for the prevalence of central obesity based on intraabdominal fat deposition (WHR). These results indicate an increase of fat mass in this population with age, and warn of an increase in obesity-related diseases in the future. WC, WHR and skinfold thicknesses increased with increasing BMI and, in the same way, with increasing central obesity (WHR). This result shows that BMI, WC and WHR could be used to indicate obesity. Also, WC, WHR and BMI were significantly correlated with all anthropometric parameters measured even after age adjustment, which indicates an association of overall obesity with central obesity in this population. WC was reported to be a practical measurement of intra-abdominal fat mass ${ }^{25}$ and to be associated with cardiovascular risk factors $6,7,10,26,27$. In this population, WC exceeding $80 \mathrm{~cm}$ was associated in women with BMI $\geq 25 \mathrm{~kg} \mathrm{~m}^{-2}(84.3 \mathrm{~cm}$ in overweight and $93.9 \mathrm{~cm}$ in obese women) and with WHR $>0.85(89.3 \mathrm{~cm})$ (Tables 5 and 6). These results support those reported previously by Lean et $a{ }^{11}$ and could be used to alert people at increased risk of cardiovascular disease who might benefit from weight management. Nevertheless, more studies are needed to address which anthropometric 


\begin{tabular}{|c|c|c|c|c|c|c|c|c|c|c|}
\hline \multirow{2}{*}{$\stackrel{\frac{⿱}{T}}{\frac{1}{3}}$} & \multirow{2}{*}{ 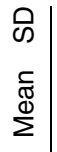 } & \multicolumn{2}{|l|}{$\overline{0} \check{0} \overline{0} \dot{0}$} & \multicolumn{7}{|c|}{$\begin{array}{l}\text { Table } 3 \text { Prevalence of obesity among Moroccan women of child- } \\
\text { bearing age based on BMI and WHR, by area of residence }\end{array}$} \\
\hline & & 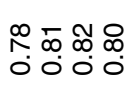 & \multirow{2}{*}{ 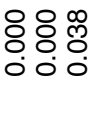 } & & \multicolumn{2}{|c|}{ Urban } & \multicolumn{2}{|c|}{ Rural } & \multicolumn{2}{|c|}{ Total } \\
\hline \multirow{4}{*}{ 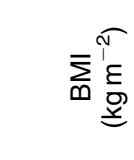 } & ผ & 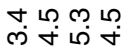 & & & $n$ & $\%$ & $n$ & $\%$ & $n$ & $\%$ \\
\hline & స్ & $\infty \nabla-\Upsilon$ & 800 & $\mathrm{BMI}^{*}$ & & & & & & \\
\hline & $\sum^{\infty}$ & N่ & 000 & Underweight & 31 & 4.7 & 32 & 4.8 & 63 & 4.7 \\
\hline & & & & $\begin{array}{l}\text { Normal weight } \\
\text { Overweiaht }\end{array}$ & $\begin{array}{l}319 \\
184\end{array}$ & $\begin{array}{l}51.4 \\
29.6\end{array}$ & $\begin{array}{l}445 \\
131\end{array}$ & $\begin{array}{l}68.9 \\
20.3\end{array}$ & $\begin{array}{l}764 \\
315\end{array}$ & $\begin{array}{l}60.2 \\
24.9\end{array}$ \\
\hline 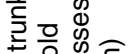 & ம & $\stackrel{\sim}{\sim} \underset{\leftarrow}{\sim}$ & & Obese & 89 & 14.3 & 39 & 6.0 & 128 & 10.1 \\
\hline ¿ & 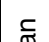 & $-N-m$ & $\stackrel{20}{N} 80$ & $\begin{array}{l}\text { WHR } \\
\quad \leq 0.85\end{array}$ & 498 & 80.1 & 567 & 87.6 & 1065 & 83.9 \\
\hline & $\sum_{i}^{\infty}$ & 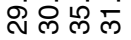 & 000 & $>0.85$ & 124 & 19.9 & 80 & 12.4 & 204 & 16.1 \\
\hline & & & & Total & 622 & & 647 & & 1269 & \\
\hline
\end{tabular}

$\mathrm{BMI}$ - body mass index; WHR - waist/hip ratio.

${ }^{*} \mathrm{BMI}$ categories - underweight, $<18.5 \mathrm{~kg} \mathrm{~m}^{-2}$; normal weight, 18.5$25 \mathrm{~kg} \mathrm{~m}^{-2}$; overweight, $>25-30 \mathrm{~kg} \mathrm{~m}^{-2}$; obese, $>30 \mathrm{~kg} \mathrm{~m}^{-2}$.

variable is the best predictor of obesity-related diseases in this population.

Although undernutrition is still relevant, the findings from this study highlight an alarming situation with regard to obesity among women in this region. This result has been reported for countries in nutrition transition ${ }^{2,4,17}$. In countries in nutrition transition such as Morocco, the increase in obesity has been attributed to changes in dietary habits, lifestyles and urbanisation ${ }^{2,3,29}$. Lifestyle and socio-economic factors also contribute to the prevalence of obesity in Moroccan women. Socioeconomic level is generally higher in urban than in rural areas. On the other hand, the results showed that urban Moroccan women had higher BMI and skinfold thicknesses than their counterparts in the rural area, which means that there is more adipose fat among urban women. Hence an association between BMI and the percentage of body fat was established ${ }^{30,32}$. The same applies to central obesity based on trunk skinfold thicknesses. General and abdominal obesity characterised both urban and rural women but was more prevalent in the urban area (Table 3). Similar results have been reported before in countries from the Gulf and North Africa for obesity based on $\mathrm{BMI}^{4,10,17,33,34}$.

Table 4 Prevalence of obesity (\%) among Moroccan women of childbearing age based on BMI and WHR, by age group

\begin{tabular}{lrrrr}
\hline & $\begin{array}{c}15-25 \\
\text { years }\end{array}$ & $\begin{array}{c}25-35 \\
\text { years }\end{array}$ & $\begin{array}{r}>35 \\
\text { years }\end{array}$ & Total \\
\hline BMI $^{*}$ & & & & \\
$\quad$ Underweight $(n=63)$ & 6.3 & 4.1 & 3.0 & 4.7 \\
$\quad$ Normal weight $(n=764)$ & 72.0 & 59.3 & 43.5 & 60.2 \\
$\quad$ Overweight $(n=315)$ & 18.1 & 25.9 & 34.2 & 24.9 \\
$\quad$ Obese $(n=128)$ & 3.6 & 10.8 & 19.3 & 10.1 \\
WHR & & & & \\
$\quad \leq 0.85(n=1065)$ & 91.9 & 82.8 & 72.9 & 83.9 \\
$>0.85(n=204)$ & 8.1 & 17.2 & 27.1 & 16.1 \\
\hline
\end{tabular}

$\mathrm{BMI}$ - body mass index; WHR - waist/hip ratio.

${ }^{*} \mathrm{BMI}$ categories - underweight, $<18.5 \mathrm{~kg} \mathrm{~m}^{-2}$; normal weight, 18.5$25 \mathrm{~kg} \mathrm{~m}^{-2}$; overweight, $>25-30 \mathrm{~kg} \mathrm{~m}^{-2}$; obese, $>30 \mathrm{~kg} \mathrm{~m}^{-2}$. 

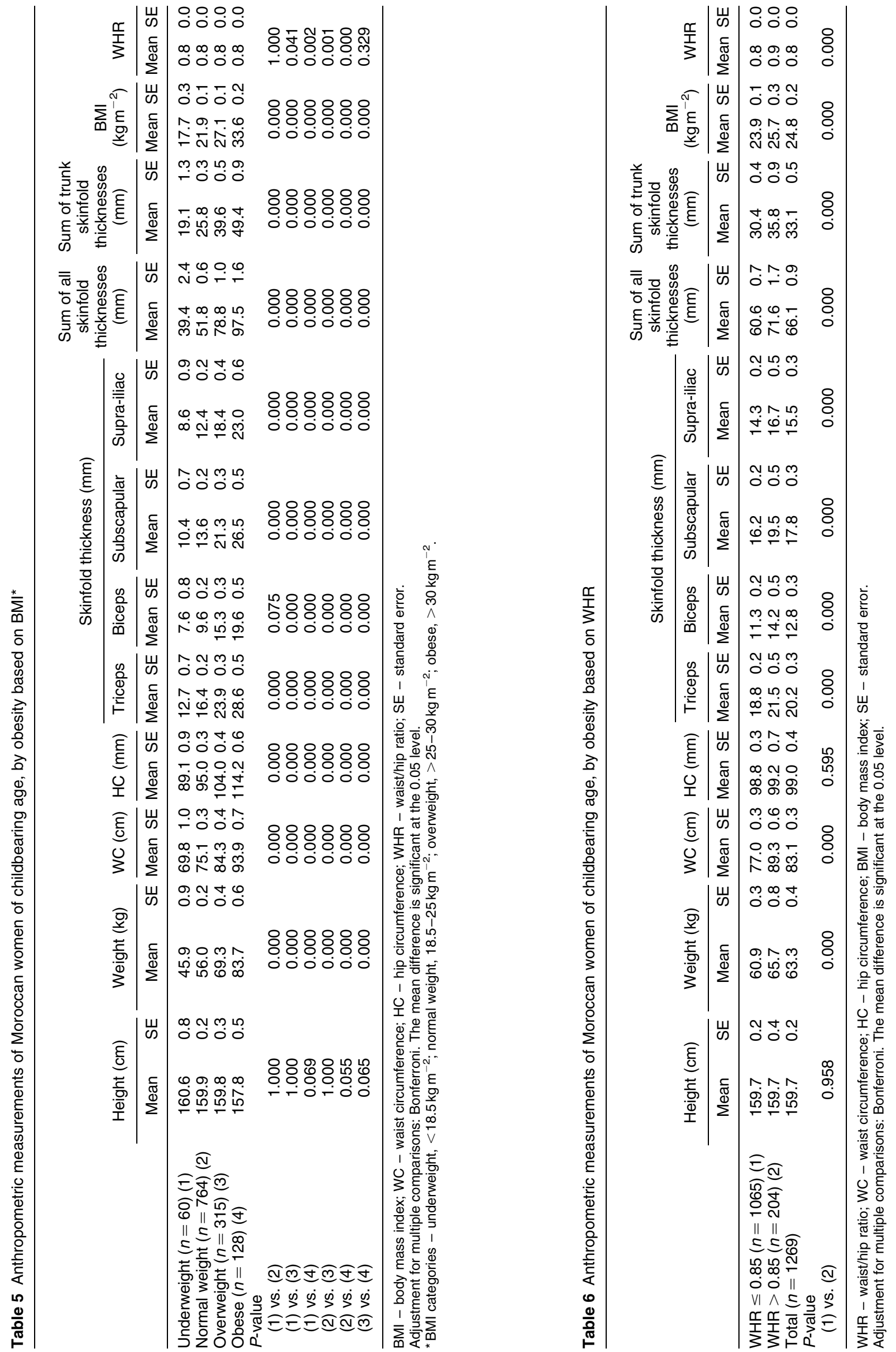
In this population, educational level seemed to be negatively correlated to body fat estimated by the sum of all skinfold thicknesses and the sum of trunk skinfold thicknesses (Table 7). The women studied here belonged to an agricultural community and only $20.5 \%$ of them were educated whereas $79.5 \%$ were without education (results not shown). The same association was reported between obesity and educational level in rural populations $s^{5,35}$. Surveys in Morocco at the national scale showed that the relationship between anthropometric status and education level is not in the same direction as that with economic status ${ }^{4}$.

Information on food consumption in populations in Morocco and other countries in the same region showed a higher calorie intake in obese and overweight women than recommended levels in the United States ${ }^{4,33,36}$.

There was no information on habitual physical activity among the Moroccan women studied, but indicators showed that women in the rural area were more active than their counterparts in the urban area, which could be an explanation for the lower prevalence of overweight and obesity in rural than urban women. In addition, development and economic modernisation in the urban area could be associated with lower physical activity. Another factor contributing to obesity in this population could be the fertility rate: the visceral obesity estimated by WC and WHR was correlated to parity. Again, the same association between general obesity and parity was found in Brazilian women ${ }^{37}$.

Ethnicity is an important factor ${ }^{38}$, as the Moroccan population is derived from many ethnic groups (Arab, Berber, Saharan) and no attempt was made in this study to determine the ethnic origin of the women studied.

\section{Conclusion}

In conclusion, our results suggest that the anthropometric parameters used here could be useful to characterise overweight and obesity (body fat and fat distribution). Although some limitations of these indicators are established, such as their relationship with sex, ethnicity, genetic factors and age ${ }^{38-40}$, these results could be useful for comparison.

The study shows that although undernutrition is still prevalent, there is an alarming prevalence of overweight and obesity in this population of women of childbearing age. The results predict a shift in Morocco from the problem of dietary deficiency to the problem of dietary excess, and alert one to the necessity of establishing an intervention to prevent obesity-related diseases by weight management, especially at young ages. More studies are needed to address which of the anthropometric variables studied here is the best predictor of obesity-related diseases in this population. 


\section{Acknowledgements}

The authors wish to thank the Director of Information and Statistics Studies Service, Rabat and the Medical Delegation of El Jadida province, Ministry of Health of Morocco, for their help with data collection. The survey was supported by the International Development Research Centre of Canada.

\section{References}

1 World Health Organization (WHO). Obesity: Preventing and Managing the Global Epidemic. Report of WHO Consultation on Obesity, 3-5 June 1997. Geneva: WHO, 1998.

2 Monteiro CA, Mondini L, Medeiros de Souza AL, Popkin BM. The nutrition transition. European Journal of Clinical Nutrition 1995; 49: 105-13.

3 Popkin BM. The nutrition transition in low income countries: an emerging crisis. Paper presented at Diet and Chronic Diseases in Countries in Socio-economic Transition, Experimental Biology Conference, Anaheim, CA, 24-28 April 1994.

4 Benjelloun S. Nutrition transition in Morocco. Public Health Nutrition 2002; 5(1A): 135-40.

5 Popkin BM, Keyou G, Fengying Z, Guo X, Haijiang M, Zohoori N. The nutrition transition in China; a crosssectional analysis. European Journal of Clinical Nutrition 1993; 47: 333-46.

6 St-Pierre J, Lemieux I, Vohl M-C, Perron P, Tremblay G, Després JP, et al. Contribution of abdominal obesity and hypertriglyceridemia to impaired fasting glucose and coronary artery disease. American Journal of Cardiology 2002; 90: $15-8$.

7 Wei M, Gaskill SP, Haffner SM, Stern MP. Waist circumference as the best predictor of noninsulin dependent diabetes mellitus (NIDDM) compared to body mass index, waist/hip ratio and other anthropometric measurements in Mexican Americans - a 7-year prospective study. Obesity Research 1997; 5(1): 16-23.

8 Deurenberg P, Andreoli A, Borg P, Kukkonen-Harjula K, de Lorenzo A, van Marken Lichtenbelt WD, et al. The validity of predicted body fat percentage from body mass index and from impedance in samples of five European populations. European Journal of Clinical Nutrition 2001; 55: 973-9.

9 Huang KC, Lin WY, Lee LT, Chen CY, Lo H, Hsia HH, et al. Four anthropometric indices and cardiovascular risk factors in Taiwan. International Journal of Obesity and Related Metabolic Disorders 2002; 26(8): 1060-8.

10 Pouliot MC, Despres JP, Lemieux S, Moorjani S, Bouchard C, Tremblay A, et al. Waist circumference and abdominal sagittal diameter: the best simple anthropometric indices of abdominal visceral adipose tissue accumulation and related cardiovascular risk in men and women. American Journal of Cardiology 1994; 73: 460-8.

11 Lean MEJ, Han TS, Morrison CE. Waist circumference as a measure for indicating need for weight management. British Medical Journal 1995; 311: 158-61.

12 Fujioka S, Matsuzawa Y, Tokunaga K, Tarui S. Contribution of intra-abdominal fat accumulation to the impairment of glucose and lipid metabolism in human obesity. Metabolism 1987; 36: 54-9.

13 Goldstone AP, Thomas EL, Brynes AE, Bell JD, Frost G, Saeed $\mathrm{N}$, et al. Visceral adipose tissue and metabolic complications of obesity are reduced in Prader-Willi syndrome female adults: evidence for novel influences on body fat distribution. Journal of Clinical Endocrinology and Metabolism 2001; 86: 4330-8.
14 Mokhtar N, Elati J, Chabir R, Bour A, Elkari K, Schlossman $\mathrm{NP}$, et al. Diet, culture and obesity in northern Africa. Journal of Nutrition 2001; 131(3): 887S-92S.

15 Ministry of Health. Government of Morocco and Ligue des États Arabes (PAPCHILD). National Survey on Mother's and Infant Health. National Report. Rabat: Ministry of Health, 1997.

16 Statistics Department, Ministry of Socio-Economic Affairs, Government of Morocco. Report of National Survey on Household Income, Consumption and Expenditure, Morocco, 1998/1999. Rabat: Ministry of Socio-Economic Affairs, 2000.

17 Galal O. Nutrition-related health patterns in the Middle East. Asia Pacific Journal of Clinical Nutrition 2003; 12(3): 337-43.

18 Direction de la Statistique. Consommation et Dépenses des Ménages 1984/1985. Vols 1, 5, 6 and 7. Rabat: Direction de la Statistique, 1992

19 World Health Organization (WHO). Measuring Obesity Classification and Description of Anthropometric Data. Report on a WHO Consultation on the Epidemiology of Obesity, Warsaw, 21-23 October 1987. Nutrition Unit Document, Eur/ICP/NUT. Copenhagen: WHO, 1987.

20 Roche AF, Heymsfield SB, Lohman TG. Human Body Composition. Champaign, IL: Human Kinetics, 1996.

21 Van der Kooy K, Seidell JC. Techniques for the measurements of visceral fat: a practical guide. International Journal of Obesity 1983; 17: 187-96.

22 Goran MI, Nagy TR, Treuth MS, Trowbridge C, Dezenberg C, McGloin A, et al. Visceral fat in white and African American prepubertal children. American Journal of Clinical Nutrition 1997; 65: 1703-8.

23 Han TS, Williams K, Sattar N, Hunt KJ, Lean ME, Haffner SM. Analysis of obesity and hyperinsulinemia in the development of metabolic syndrome: San Antonio Heart Study. Obesity Research 2002; 10(9): 923-31.

24 Roche Foundation and Ministry of Health, Government of Morocco. Obesity in Morocco, Preliminary Report 1999. Rabat: Ministry of Health, 1999.

25 Seidell JC. Are abdominal diameters abominable indicators? In: Angel A, Bouchard C, eds. Progress in Obesity Research. London: Libbey, 1995; 303-6.

26 Han TS, van Leer EM, Seidell JC, Lean ME. Waist circumference action level in the identification of cardiovascular risk factors: prevalence study in a random sample. British Medical Journal 1995; 311: 1401-5.

27 Zhu S, Wang Z, Heshka S, Heo M, Faith MS, Heymsfield SB. Waist circumference and obesity-associated risk factors among whites in the third National Health and Nutrition Examination Survey: clinical action thresholds. American Journal of Clinical Nutrition 2002; 76(4): 743-9.

28 Björntorp P. Metabolic implications of body fat distribution. Diabetes Care 1991; 14: 1132-43.

29 World Health Organization (WHO). Diet, Nutrition and the Prevention of Chronic Diseases. Technical Report Series No. 797. Geneva: WHO, 1990.

30 Musaiger AO, Al-Ansari M, Al-Manal M. Anthropometry of adolescent girls in Bahrain, including body fat distribution. Annals of Human Biology 2000; 27(5): 507-15.

31 Al-Rehaimi AA, Bjorntorp P. Obesity and fat distribution in women from Saudi Arabia. International Journal of Obesity and Related Metabolic Disorders 1992; 16(12): 1017-9.

32 Blew RM, Sardinha LB, Milliken LA, Teixeira PJ, Going SB, Ferreira DL, et al. Assessing the validity of body mass index standards in early postmenopausal women. Obesity Research 2002; 10(8): 799-808.

33 Institut National de Nutrition et de Technologie Alimentaire et le Ministère de la Santé Publique. National Survey Report on Nutritional Status of Tunisian Population. Tunis: Ministry of Health, 1997. 
34 Ghassemi H, Harrison G, Mohammad K. An accelerated nutrition transition in Iran. Public Health Nutrition 2002; 5(1A): $149-55$.

35 Molarius A, Seidell JC, Sans S, Tuomielehto J, Kuulasmaa K. Educational level, relative body weight, and changes in their association over 10 years: an international perspective from the WHO MONICA project. American Journal of Public Health 2000; 90(8): 1260-8.

36 US Department of Health and Human Services. US Dietary Guidelines, Internet Edition [online], 1994. Available at http://www.dhhs.gov.

37 Coitinho DC, Sichieri R, D'Aquino Benicio MH. Obesity and weight change related to parity and breast-feeding among parous women in Brazil. Public Health Nutrition 2001; 4(4): $865-70$.
38 Okusun IS, Tedders SH, Choi S, Dever G. Abdominal adiposity values associated with established body mass indexes in white, black and Hispanic Americans. A study from the third National Health and Nutrition Examination Survey. International Journal of Obesity and Related Metabolic Disorders 2000; 24: 1279-85.

39 Baumgartner RN, Heymsfield SB, Roche AF. Human body composition and the epidemiology of chronic disease. Obesity Research 1995; 3: 73-95.

40 Bar-Or O, Foreyt J, Bouchard C, Brownell KD, Dietz WH, Ravussin E, et al. Physical activity, genetic and nutritional consideration in childhood weight management. Medicine and Science in Sports and Exercise 1998; 30: 2-10. 